\title{
ESTUDO NA REDUÇÃO DO BANDEAMENTO E ESTABILIZAÇÃO DOS RESULTADOS DE IMPACTO PARA O AÇO SAE 8620MOD*
}

Gabriel Filipe Barrelas Marques Gamito Cardoso ${ }^{1}$ Jeferson da Silva Gomes ${ }^{2}$ Leila Teichmann ${ }^{3}$

\section{Resumo}

O aço em estudo (SAE8620MOD) é um material utilizado na aplicação de estruturas de óleo e gás. Essa liga modificada é utilizada em estruturas off-shore para produção de amarras. Para garantir a qualidade do produto são realizadas uma série de ensaios, dentre eles propriedades mecânicas (RT, LE, Alongamento e redução de área) bem como resultados de dureza e impacto. O ensaio de impacto está relacionado diretamente com a microestrutura obtida durante o processo de solidificação do aço e com o tratamento térmico realizado. Microestruturas com alto grau de bandeamento podem comprometer a variabilidade dos resultados de impacto. A redução ou até mesmo a eliminação do bandeamento é um caso de amplo estudo, principalmente em aços com processo de lingotamento contínuo. Muitas soluções já foram propostas para a redução do bandeamento, o de agitação eletromagnética tem se mostrado bastante efetivo na redução dos níveis de bandeamento e segregação dos produtos lingotados. $O$ ensaio consiste em avaliar a intensidade do campo eletromagnético (FEMS) para o comportamento do nível de bandeamento do material. Foi utilizada uma corrida para teste via lingotamento contínuo, onde a velocidade de lingotamento permaneceu constante e variou-se a corrente dos agitadores em três condições: tarugos com baixa agitação (FEMs com corrente baixa), tarugos com alta agitação (FEMS com corrente alta) e tarugos sem agitação (FEMS desligado). Com baixa agitação no FEMS conseguimos obter um nível de bandeamento menor se comparado com os outros resultados. Como consequência a variação dos valores de impacto apresentaram-se menores que as demais condições, devido a homogeneidade do material. Dessa forma podemos dizer que a redução do nível de bandeamento no material reduziu também a variação dos resultados de impacto, tornando o processo mais estável.

Palavras-chave: Impacto; Aço SAE 8620MOD; FEMs.

\section{STUDY ON THE REDUCTION OF FLAG AND STABILIZATION OF THE IMPACT RESULTS FOR SAE 8620MOD STEEL}

\section{Abstract}

The steel under study (SAE8620MOD) is a material used in the application of oil and gas structures. This modified alloy is used in offshore structures for the production of moorings. In order to guarantee the quality of the product, a series of tests are carried out, among them mechanical properties (RT, LE, Stretching and area reduction) as well as hardness and impact results. The impact test is directly related to the microstructure obtained during the solidification process of the steel and to the heat treatment performed. Microstructures with high degree of banding can compromise the variability of impact results. The reduction or even the elimination of the banding is a case of ample study, mainly in steels with continuous casting process. Many solutions have already been proposed for the reduction of the banding, the electromagnetic agitation has shown to be quite effective in reducing the levels of banding and segregation of the ingot products. The test consists in evaluating the intensity of the electromagnetic field (FEMS) for the behavior of the level of banding of the material. A run for testing was conducted by continuous casting, where the casting speed remained constant and the agitators current varied in three conditions: low stirring billets (FEMs with low current), high bending billets (FEMS with high current) And billets without agitation (FEMS off). With low agitation in the FEMS we were able to obtain a lower level of banding when compared to the other results. As consequence, the variation of the impact values was lower than the other conditions, due to the homogeneity of the material. In this way we can say that the reduction of the level of banding in the material also reduced the variation of the impact results, making the process more stable.

Keywords: Impact; Steel SAE 8620MOD; FEMs 
1 Engenheiro Metalúrgico/UFRGS. Mestre em Engenharia de Minas, Metalúrgica e de Materiais/UFRGS, Assessor Técnico, PD\&I/TAE, Gerdau, Porto Alegre/RS, Brasil.

2 Técnico em Metalurgia, Assistente de Processo, PD\&I/TAE, Gerdau, Charqueadas/RS, Brasil.

3 Engenheira Metalúrgica/UFRGS. Doutoranda em Engenharia de Minas, Metalúrgica e de Materiais/UFRGS, Assessora Técnica, PD\&I/TAE, Gerdau, Porto Alegre/RS, Brasil. 


\section{INTRODUÇÃO}

A versatilidade e a aplicabilidade do aço fazem com que seja uma das matérias-primas mais utilizadas no mundo. Dentre elas está a aplicação em amarilhas para estrutura off-shore. Atualmente uma grande parte do suprimento mundial de petróleo é proveniente de operações off-shore [1]. Uma das aplicações para aços SAE 8620 MOD é a aplicação de amarras para essas estruturas. Abaixo podemos ver (Figura 1) o produto produzido com aço citado.
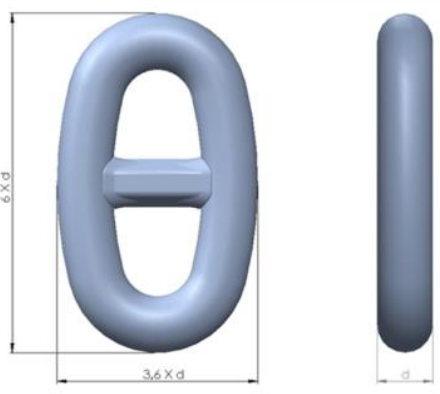

Elo Comum com Malhete

Figura 1. Amarras - produto final.

O processo de produção das amarras pode ser via lingotamento contínuo, na forma de tarugos de seção quadrada. Os tarugos produzidos em Aciaria podem apresentar uma ocorrência de segregação química e bandeamento oriundos do próprio processo de lingotamento. Uma forma de ser reduzir o feito do bandeamento em aços é a utilização de agitadores eletromagnéticos.

O processo subsequente, após os tarugos é a laminação dos mesmos na forma de barras, sendo estas o produto final de usina. $O$ ensaio de impacto avalia 0 comportamento dúctil ou frágil do material que está sendo avaliado. Esse comportamento está relacionado diretamente com a temperatura em que o ensaio é realizado. Para essa temperatura dá-se o nome de Temperatura de Transição DúctilFrágil (TTDF) dos materiais. Esse efeito pode estar relacionado diretamente com a variação microestrutural. $O$ bandeamento associada a microestrutura são um dos responsáveis pela variação dos resultados obtidos.

\subsection{Agitação Eletromagnética}

A utilização de agitadores eletromagnéticos tem sido bastante efetiva na redução de níveis de segregação e bandeamento para com produtos via lingotamento contínuo. Os agitadores podem ser colocados em diferentes pontos do raio de curvatura da máquina de LC, de forma a atuar sobre a última porção de material líquido a se solidificar. São normalmente denominados conforme sua posição. Segue: MEMs agitadores eletromegnéticos no molde. SEMs - agitadores eletromegnéticos ao longo do veio e FEMs - agitadores eletromagnéticos finais, próximos a zona de solidificação conforme apresentado na Figura 2 abaixo. [2]

Com relação ao agitador eletromagnético final - FEMs, preponderante na realização de experimentos via LC, podemos abaixo ver na Figura 3 algumas das distintas configurações para à utilização desse equipamento, que pode ser visto ao longo do posicionamento do raio de curvatura da máquina de lingotamento contínuo. 


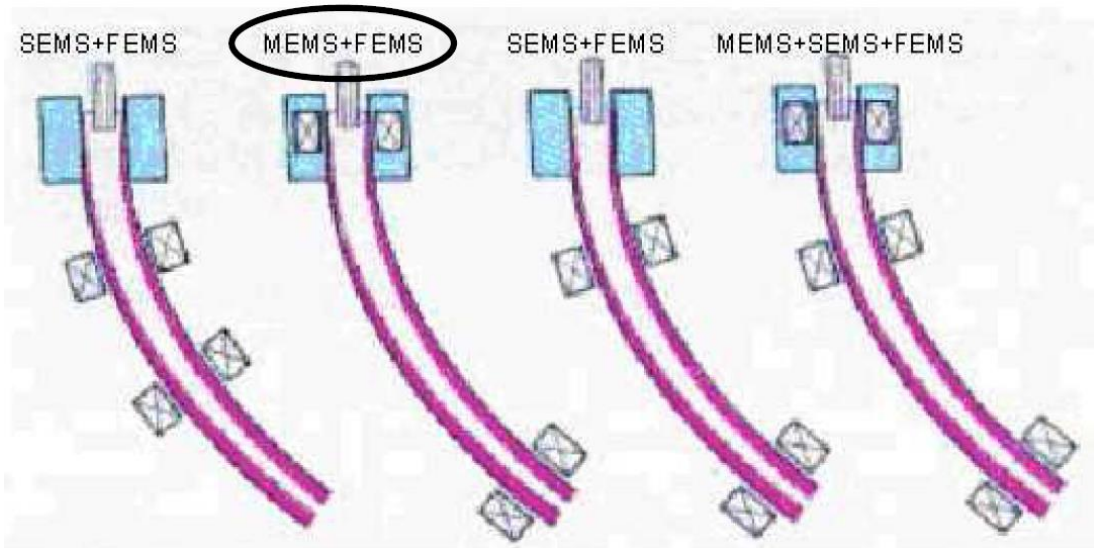

Figura 2. Tipos de agitadores eletromagnéticos [2]

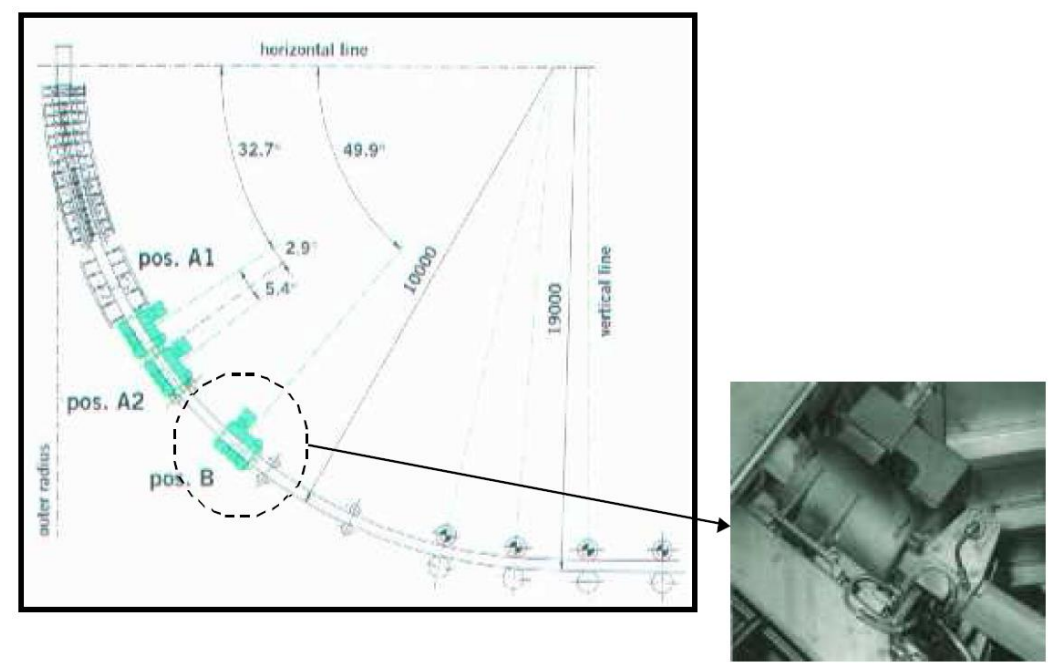

Figura 3. Configurações possíveis para a utilização do FEMs. [3]

Analisando-se mecanicamente a atuação da agitação eletromagnética do banho proporcionada pela ação do campo eletromagnético do FEMs, sabe-se que a mesma age sobre o crescimento colunar dos cristais da frente de solidificação, quebrando as pontes de solidificação formadas nos estágios finais do processo, a partir do momento em que o crescimento colunar dos cristais alcança o eixo central de solidificação do tarugo, prevenindo a natural solidificação irregular com formação de porosidades e/ou mini lingotes. Além disso a quebras das pontes de solidificação permite 0 preenchimento das cavidades formadas, decorrentes do fenômeno de contração, com uma nova quantidade de aço líquido. Com isso, o líquido inter-dendrítico segregado pode misturar com essa nova quantidade de aço que está sendo alimentada pelos canais (vide modelo de solidificação proposto por IRSID [3] na Figura 4). Como efeito final tem-se uma maior homogeneização do aço líquido ao final da solidificação. $O$ resultado disso pode ser observado não só na redução dos picos de segregação central como também na redução da porosidade central dos tarugos.

Por outro lado, deve-se levar em conta a questão térmica quando se fala de agitação eletromagnética, principalmente devido ao fato desta agir em menor intensidade como "quebrador de dendritas", situação abordada pela análise mecânica e mais com um dissipador de calor, melhorando a transferência de calor para a pele solidificada e desta para o molde de cobre/água. Sendo o superaquecimento dissipado, facilita a nucleação de pequenos cristais equiaxiais. Com isso, minimiza-se a formação da região colunar - e por consequência a possibilidade de formação das pontes de 
solidificação, segregação e porosidades centrais. O resultado final é uma estrutura mais refinada. $O$ que se observa é que a agitação eletromagnética consegue reduzir significativamente os teores de bandeamento em tarugos lingotados.

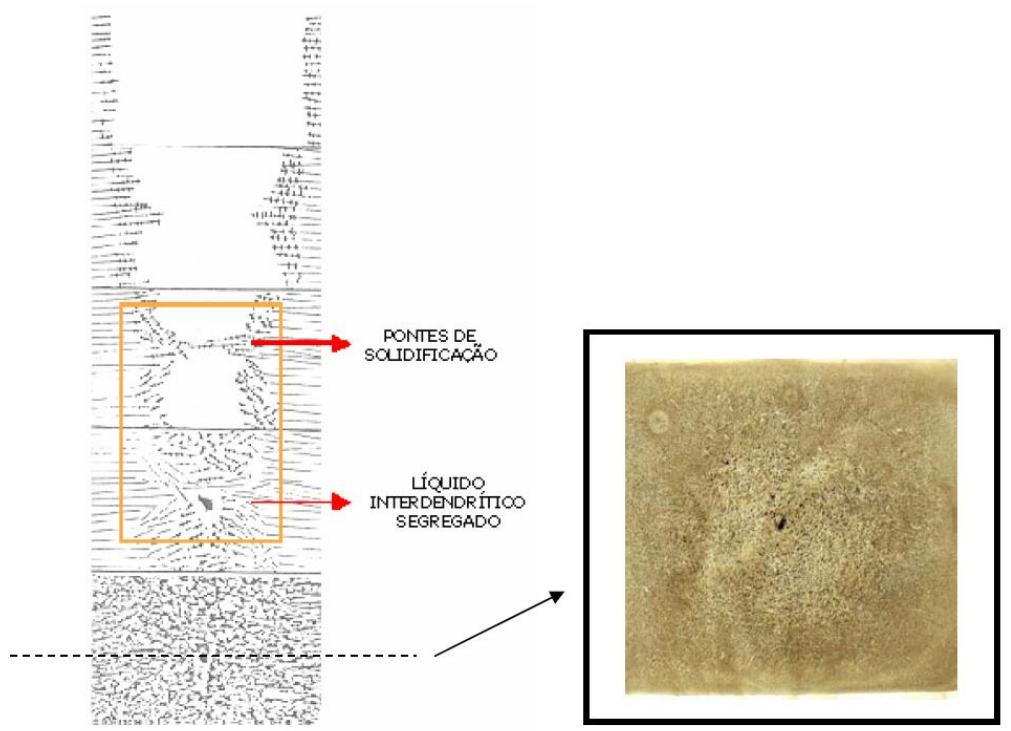

Figura 4. Distribuição típica de inclusão Modelo de solidificação natural sem agitação eletromagnética proposto pelo IRSID. No detalhe, estrutura bruta de solidificação resultante de impressão de Baumann realizada na seção transversal de um tarugo de LC. [3]

\subsection{Propriedades Mecânicas de Impacto}

O interesse para o estudo desse ensaio surgiu na segunda guerra mundial, quando se observou que no inverno alguns navios partiam-se ao meio, apresentando estrutura frágil, tendo estes sido construídos com juntas soldadas de materiais com boa ductilidade, quando ensaiadas a temperatura ambiente. Abaixo, na Figura 5, podemos ver um navio com esse tipo de fratura catastrófica. [4]

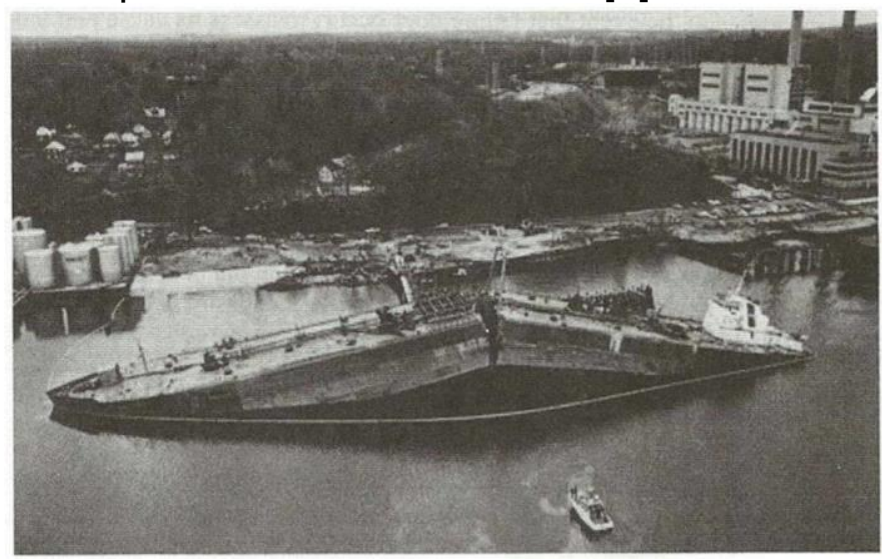

Figura 5. Navio com ruptura frágil. [5]

O ensaio Charpy foi o ensaio que melhor se adequava as necessidades do estudo de fratura catastrófica, sendo até hoje o ensaio com ampla utilização para esse fim. Levantando-se dados de absorção de energia de um material metálico, em diversas temperaturas, podemos determinar a temperatura de transição dúctil frágil do material. A temperatura de transição dúctil frágil (TTDF) nada mais é os limites abaixo da qual o comportamento a fratura do material se altera de dúctil para frágil, de maneira a se evitar ocorrências de fratura frágil catastróficas. Abaixo na Figura 6 podemos ver um 
material ensaiado a 4 diferentes temperaturas por ensaio de impacto Charpy. É possível verificar que a face de fratura se apresenta de diferentes maneiras, variando de uma fratura 100\% brilhante (fratura frágil) para uma 100\% opaco (fratura dúctil). [4]

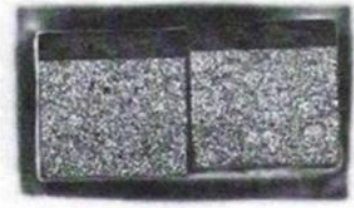

(a)

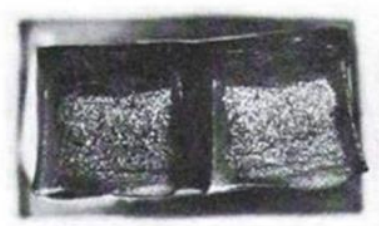

(c)

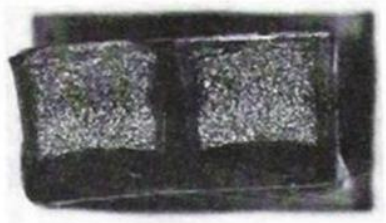

(b)

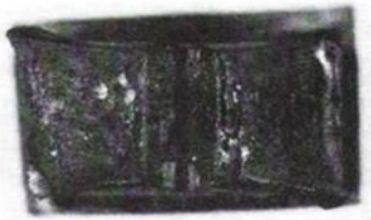

(d)

Figura 6. Faces de uma fratura para um material ensaiado em diversas temperaturas.

A separação ou fragmentação de um corpo sólido em duas partes, pela ação de um esforço é chamada de fratura e a capacidade de absorver energia até que essa fratura ocorra é a tenacidade do material que constitui o corpo sólido. O ensaio consiste em promover uma queda de um pêndulo de uma altura conhecida sobre a peça que se quer ensaiar. Abaixo na Figura 7 podemos ver um desenho esquemático do equipamento para o ensaio. [4]

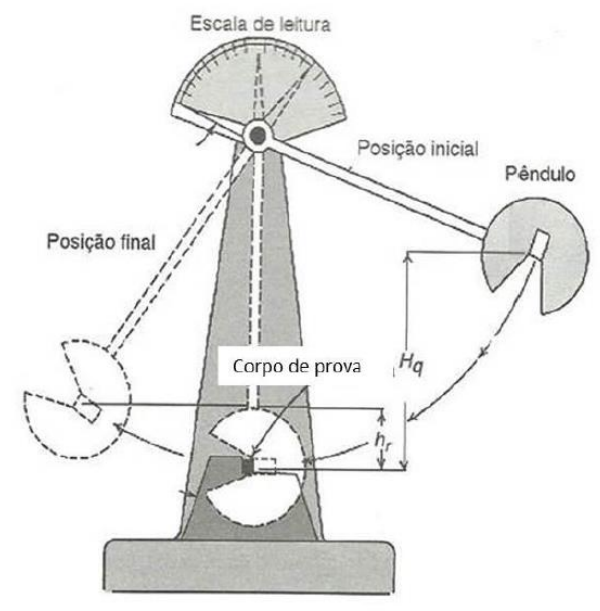

Figura 7. Equipamento para um ensaio de impacto.

O pêndulo é liberado de uma altura conhecida - posição inicial e se choca com o corpo de prova. Após esse choque o pêndulo sobe novamente até uma altura menor que a inicial - posição final. A energia absorvida pelo impacto do corpo de prova equivale à energia perdida pelo pêndulo no momento do impacto, que se revela pela perda de altura.

O número de variáveis que podem afetar a temperatura de transição do aço é grande. Uma das mais importantes é a microestrutura do material. Um exemplo típico do efeito da microestrutura é mostrado na Figura 8, onde a comparação é feita entre duas resistências de impacto, em função da temperatura, para o mesmo aço, submetido a dois tratamentos térmicos diferentes. 


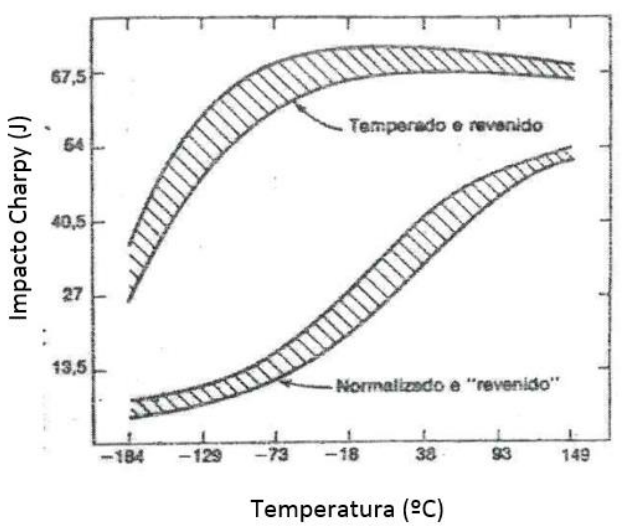

Figura 8. Efeito de dois tratamentos térmicos sobre a resistência ao impacto à baixa temperatura de um aço de médio carbono ligado (4340).

Os dois tratamentos térmicos produziram no material a mesma dureza. Em um aço foi temperado e revenido para produzir cementita esferoidizada, e no outro aço foi normalizado (resfriado ao ar) e a seguir revenido para produzir perlita. A diferença entre as duas estruturas é evidente. A temperatura de transição é aproximadamente $170^{\circ} \mathrm{C}$ mais baixa para estrutura esferoidizada, o que constitui uma forte razão para que peças e máquinas, nas quais a tenacidade é uma propriedade importante, sejam tratadas termicamente [5].

Não só a microestrutura do material, mas também o bandeamento (alternância de regiões martensitícas e bainíticas) que pode ocorrer em materiais temperados, oriundo da máquina de LC, pode também gerar uma variação nos resultados de impacto.

\section{MATERIAIS E MÉTODOS}

$O$ aço utilizado nesse estudo foi produzido em um usina semi-integrada. O processo de aciaria se inicia na escolha da matéria-prima (sucata, gusa sólido, fundentes, entre outros) para fabricação do aço via FEA (forno elétrico a arco). No FEA é feito o refino primário, onde ocorre basicamente a desfosforação do aço. Após o término desta etapa, o aço vai para o refino secundário, que consiste na dessulfuração do aço. Após isso, a panela é levada ao desgaseificador à vácuo para redução dos teores de hidrogênio, nitrogênio e oxigênio basicamente. Depois disso, o aço líquido é destinado ao lingotamento contínuo, onde ocorre a solidificação do aço. O resumo do processo na aciaria pode ser visto na Figura 9.

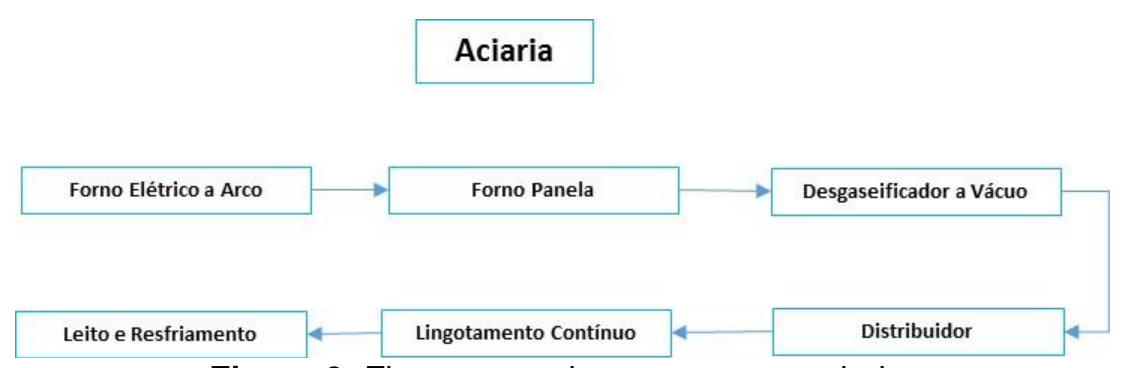

Figura 9. Fluxograma do processo na aciaria. 


\subsection{Produção do aço}

A qualidade de aço escolhido para o estudo desse trabalho foi um aço SAE 8620 MOD, via lingotamento contínuo com a utilização de FEMs. Com o objetivo de se obter estabilidade dos resultados de impacto.

As amostras de aço líquido foram retiradas para análise de composição química. Tal análise foi necessária para saber se a composição química estava dentro das especificações solicitadas.

A máquina de lingotamento contínuo é curva, com molde de seção quadrada de 240 $\mathrm{mm}$ de lado na seção transversal e com três zonas de resfriamento: no molde, na zona de sprays d'água e no leito de resfriamento. O vazamento da panela para o distribuidor é feito através do tubo longo. O distribuidor é protegido por uma tampa e o vazamento do mesmo para o molde é feito através da válvula submersa. Esses recursos visam prevenir a reoxidação do aço. Ao longo do processo de solidificação, o tarugo passa por agitadores eletromagnéticos para homogeneização química e para quebra da estrutura colunar, resultando em grãos mais finos e com composição química mais homogênea. Essa variação está relacionada diretamente ao nível de agitação realizada, ou seja, a corrente que é aplicada no material.

\subsection{Amostragem}

As amostras foram mapeadas no lingotamento contínuo, utilizando os parâmetros atuais para o aço SAE 8620MOD de velocidade, super heat e temperatura de lingotamento. Para os FEMs utilizou-se três tipos de condição: condição desligado, FEMs com corrente baixa e FEMs com corrente alta. Na Figura 10 podemos ver a disposição e a forma como os tarugos forma mapeados.
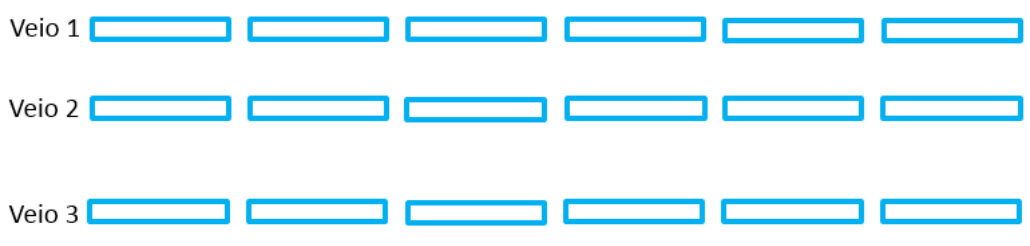

FEMS Baixo
FEMS Desligado

FEMS Alto

Figura 10. Teste realizado com FEMs no LC.

As amostras foram mapeadas por veio e retiradas nas etapas de laminação (barra laminada) nas serras dispostas em cada área. Foram retiradas duas amostras por veio para avaliação dos seguintes ensaios: dureza, propriedades mecânicas (RT, LE, alongamento e redução de área), impacto e macrografia. A Tabela 1 resume as informações a respeito das amostras.

Tabela 1. Retirada das Amostras

\begin{tabular}{|c|c|c|c|c|}
\hline TIPO & VEIO & No AMOSTRAS & BITOLA & REGIÃO DE RETIRADA NA BARRA \\
\hline \multirow{3}{*}{ Aço Laminado } & 1 & 2 & 123 & Indiferente \\
\cline { 2 - 5 } & 2 & 2 & 123 & Indiferente \\
\cline { 2 - 5 } & 3 & 2 & 123 & Indiferente \\
\hline
\end{tabular}

As amostras retiradas das barras possuem comprimento de $290 \mathrm{~mm}$ por $123 \mathrm{~mm}$ de diâmetro. Após as amostras vão para o laboratório e são submetidas a um ciclo de tratamento térmico de normalização, tempera e revenimento. São retiradas amostras para ensaio de tração e impacto charpy. Na Figura 11 podemos ver o croqui de ensaio bem com a região de retirada dos corpos de prova para ensaio. 


\subsection{Equipamentos}

Para a análise das microestruturas foi utilizado o microscópio ótico - Olympus BX60 M com analisador de imagem Leica QWin. Para os ensaios de tração utilizamos o equipamento Instron 300LX - B1 - C4 com o software Bluehill. Par aos ensaios de impacto foi utilizado a máquina MOHR \& FEDERHAFF tipo PWS 3015.

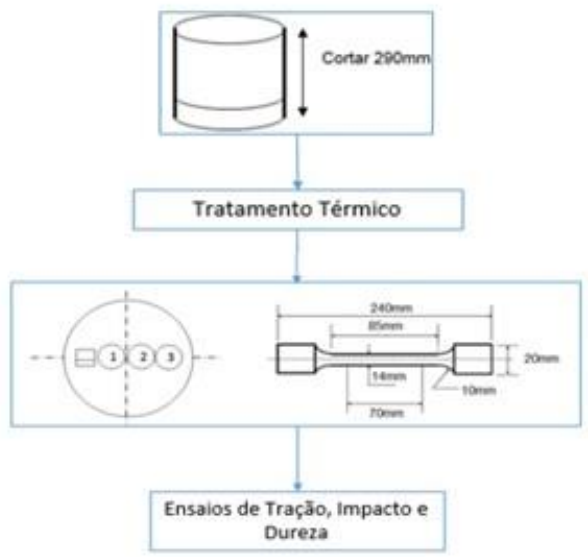

Figura 11. Retirada de amostras para ciclo de tratamento térmico e ensaios de tração, impacto.

\section{RESULTADOS E DISCUSSÃO}

As amostras foram retiradas de barras laminadas seguindo os parâmetros conforme Figura 10 (veio 1 com FEMs Baixo, veio 2 com FEMs deligado e veio 3 com FEMs alto). O local da retirada dos corpos de prova das barras foi realizado conforme Figura 11.

Abaixo podemos avaliar os resultados obtidos para cada ensaio.

\subsection{Propriedades Mecânicas}

As amostras foram retiradas de barras laminadas conforme Figura 11 e tracionadas conforme norma W22 - Offshore Mooring Chain IACS Req.1993/Rev.5_Corr.1 2011 [6]. Segue resultados dos ensaios seguindo os parâmetros realizados por veio.

Tabela 2. Resultados de Tração por veio e FEMs

\begin{tabular}{|c|c|c|c|c|c|}
\hline FEMS & Veio & RT (MPa) & LE (MPa) & RED AREA (\%) & ALONG (\%) \\
\hline Baixo & 1 & 889 & 798 & 61 & 14 \\
\hline Desligado & 2 & 940 & 865 & 63 & 16 \\
\hline Alto & 3 & 923 & 833 & 63 & 14 \\
\hline
\end{tabular}

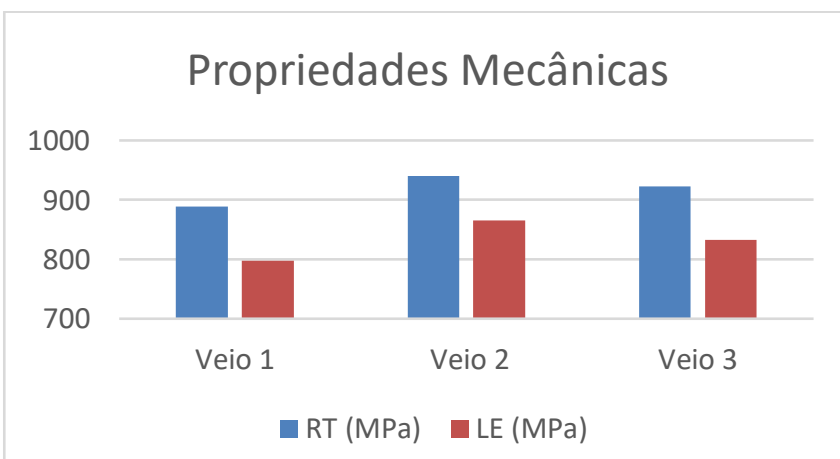

Figura 12. Gráfico com os resultados de tração analisados por veio. 
Podemos perceber uma diferença nos resultados do primeiro veio em relação aos demais veios. Houve uma redução nos resultados de $5,4 \%$ para a resistência a tração se comparado com o veio 2 e se comparado com o veio 3 houve uma redução de $3,6 \%$.

\subsection{Ensaio de Impacto}

As amostras foram retiradas conforme Figura 11 e ensaiadas conforma norma W22 Offshore Mooring Chain IACS Req.1993/Rev.5_Corr.1 2011 (7). Abaixo podemos ver os resultados de impacto para cada veio.

Tabela 3. Resultados de Impacto por veio e FEMs

\begin{tabular}{|c|c|c|c|c|}
\hline FEMS & Veio & AMOSTRA 1 & AMOSTRA 2 & AMOSTRA 3 \\
\hline Baixo & 1 & 118 & 120 & 116 \\
\hline Desligado & 2 & 103 & 118 & 118 \\
\hline Alto & 3 & 124 & 132 & 118 \\
\hline
\end{tabular}

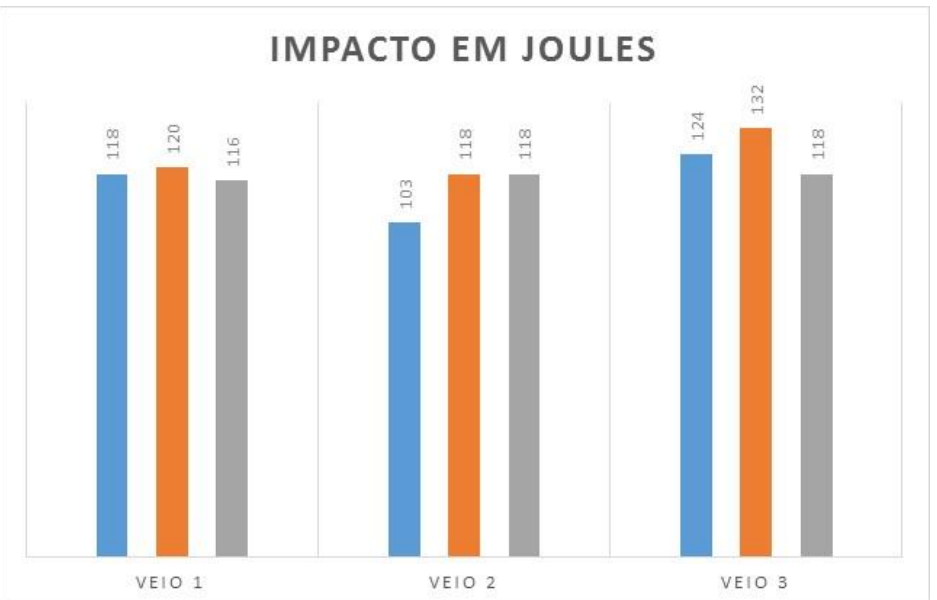

Figura 13. Gráfico com os resultados de impacto analisados por veio.

Os resultados de impacto para o material apresentado estão com valores acima de 100J, com média de 118J. Os valores apresentados indicam uma TTDF resultante de um material com presença de fase martensítica em sua estrutura. Abaixo podemos observar a variação dos resultados de impacto por veio. Podemos perceber, conforme Figura 14, que o veio 1 apresentou uma variação de resultados de impacto bem menor se comprado com os demais veios. Houve uma redução de variação de $70 \%$ quando comparado com os demais veios.

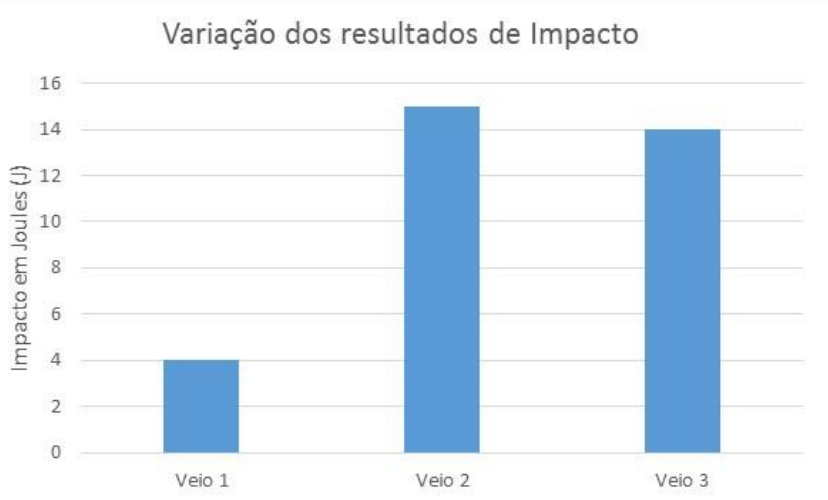

Figura 14. Gráfico da variação dos resultados de impacto por veio. 


\subsection{Microestruturas e Macrografia}

Abaixo na Figura 15 podemos ver as macrografias realizadas por veio. Podemos observar ausência de banda branca e baixa segregação central.

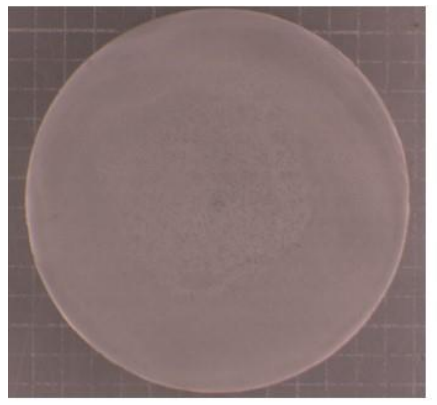

Veio 1 - FEMs Baixo

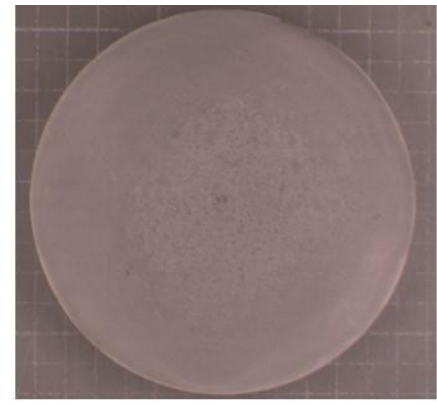

Veio 2 - FEMs Desligado

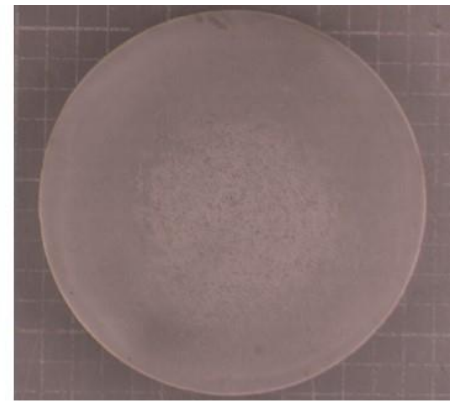

Veio 3 - FEMs Alto

Figura 15. Macrografias. Ataque Nital $5 \%$.

$\mathrm{Na}$ Figura 16 podemos ver as microestruturas realizadas nos corpos de prova utilizados para o ensaio de impacto. Nas microestruturas conseguimos ver não só o bandeamento, mas também a sua intensidade.

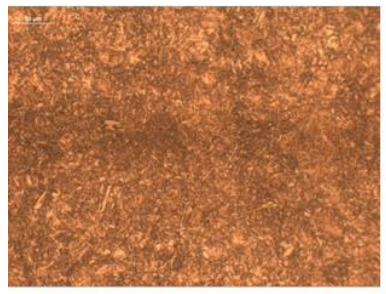

Veio 1 - FEMs Baixo

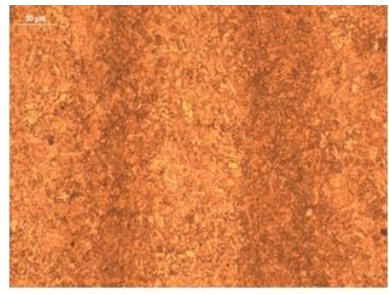

Veio 2 - FEMs Desligado

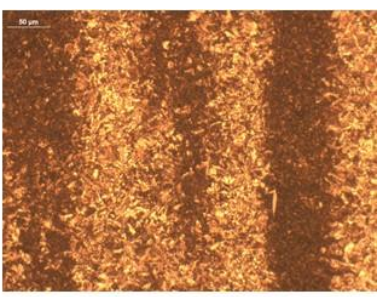

Veio 3 - FEMs Alto

Figura 16. Microestruturas tratadas a $1 / 2$ raio na longitudinal. Aumento de $200 \mathrm{x}$. Ataque Nital $5 \%$.

\subsection{Correlação entre Microestruturas, Impacto e Propriedades Mecânicas}

Ao comparamos as microestruturas dos veios 1, 2 e 3, percebemos que a quantidade de bandas no veio 1 foi menor que nos veios 2 e 3 . As bandas mais escuras detectadas são resultado de uma presença de estrutura martensítica. As fases mais claras possuem presença de estrutura bainítica. Essa diferença de fases na microestrutura contribui de uma forma direta para os resultados de impacto. Apesar dos resultados estarem com valores de TTDF altos (acima de 100J mínimo), percebemos que uma estrutura mais homogênea (encontrada no veio 1) melhorou de uma forma significativa a repetitividade dos resultados de impacto analisados. Ou seja, a microestrutura por estar mais uniforme contribuiu para que os resultados fossem mais homogêneos se comprados com os resultados dos veios 2 e 3 . A microestrutura é uma das principais variáveis para análise dos resultados de impacto. Ao compararmos os resultados de propriedades mecânicas entre os veios 1, 2 e 3, podemos perceber que o resultado do veio 1 possui valor menor se comprado com os demais veios. Isso pode estar correlacionado com a quantidade de bandeamento encontrado nos veios 2 e 3 . As bandas por ser de uma estrutura martensítica possuem uma dureza mais elevada se comprada com a estrutura banítica (fase mais clara). Essa diferença de bandas, quando aplicada as tensões de tração no corpo de prova contribuem para que haja um aumento de resistência mecânica quando ocorre a 
geração dos planos de escorregamento no material e a formação da região de estricção. No veio 1, por não termos uma quantidade significativa de bandas, o feito não é verificado.

\section{CONCLUSÕES}

Podemos perceber que os resultados de propriedades mecânicas (resistência a tração, limite de escoamento, alongamento e redução de área) e impacto tiveram influência direta com a aplicação dos FEMs. Podemos perceber que os resultados de bandeamento do veio 1 quando comprados com o veio 2 e 3 é menor. Essa homogeneidade verificada no veio 1 é explicada com baixa variação nos resultados de impacto, bem como o valor de resistência a tração e limite de escoamento. Também foram menores quando comprados com os demais veios. Essa homogeneidade pode ser explicada devido à quantidade de corrente aplicada que neste caso utilizou-se uma baixa corrente. A mesma agiu sobre o crescimento colunar dos cristais da frente de solidificação de uma maneira mais eficiente do que com a corrente mais alta (veio 3) e sem a utilização do FEMs (veio 2). Essa eficiência contribuiu com a prevenção da solidificação irregular na formação de mini lingotes e homogeneização do líquido inter-dendrítico segregado. Este líquido consegui misturar-se de uma maneira mais homogênea ao final da solidificação. Dessa forma, percebe-se uma redução do nível de bandeamento encontrado no veio 1 quando comparado com os demais veios.

Em suma, com este trabalho conseguimos avaliar o comportamento da aplicação dos FEMs frente a quantidade de bandeamento encontrado. Percebe-se uma correlação direta entre os resultados da microestrutura encontrada com os resultados de impacto e tração.

\section{Agradecimentos}

À Gerdau por todo auxílio ao longo da pesquisa.

\section{REFERÊNCIAS}

1 Fagundes D. Modelagem Física de Estruturas Offshore assentes em leito marinho. Dissertação de Mestrado, COPPE, 2010.

2 Cappellari A. Estudo da Formação de trincas internas centrais em barras laminadas em aço SAE 1141, Dissertação de Mestrado, UFRGS, 2006.

3 Celiberto A M, Carnino V, Janoski JL, Santos FC, Soares RB, Parreira FJD. Aplicação do Final Eletromagnetic Stirrer (FEMs) na produção de aços Especiais da Gerdau S/A - Aços finos Piratini. XXXIV Seminário de Refino e Solidificação dos Metais. Belo Horizonte, 2003.

4 Gouveia KC, Investigação dos métodos de determinação da temperatura de transição dúctil-frágil (TTDF) utilizando ensaio de impacto Charpy. Dissertação de Mestrado. FEl, 2013.

5 Reed-Hill RE, Princípios de Metalurgia Física. Segunda Edição. 1973.

6 W22 - Offshore Mooring Chain IACS Req.1993/Rev.5_Corr.12011. 